\title{
TINJAUAN PENYEBARAN TRADISI LISAN DI SUMATERA BARAT
}

\author{
Utari Akhir Gusti*, Audy Islami², Ardi ${ }^{3}$, Aina Almardiyah4, Ranti Gusti Rahayu5 ${ }^{5}$, Opi Tananda6 \\ 1,2,3 Biologi, Universitas Negeri Padang, Kota Padang Sumatera Barat, Indonesia \\ ${ }_{4}^{4}$ Teknologi Pendidikan, Universitas Negeri Padang, Kota Padang Sumatera Barat, Indonesia \\ 5 Kimia, Universitas Negeri Padang, Kota Padang Sumatera Barat, Indonesia \\ 6 Teknik Otomotif, Universitas Negeri Padang, Kota Padang Sumatera Barat, Indonesia \\ e-mail: utariakhir@gmail.com
}

\begin{abstract}
Abstrak
Budaya adalah bagian terpenting dalam kehidupan yang harus dilestarikan dan dijaga dengan baik. Salah satu dari 10 objek pemajuan kebudayaan (OPK) yang harus dilestarikan yaitu tradisi lisan. Masalah yang ditemukan terkait tradisi lisan yaitu makin sedikitnya masyarakat yang mengetahui tradisi lisan dan penuturnya pun sangat jarang menulis dan publikasi. Berdasarkan PPKD Sumatera Barat, kondisi tradisi lisan saat ini perlu usaha untuk mengumpulkan tradisi lisan yang ada untuk dikembangkan, sehingga dapat dilakukan invetarisasi tradisi lisan Sumatera Barat. Oleh karena itu, dilakukanlah penelitian mengenai tinjaun penyebaran tradisi lisan di Sumatera Barat. Jenis penelitian adalah penelitian kualitatif dengan teknik pengumpulan data yaitu pengamatan dan dokumentasi, observasi, studi literature, serta wawancara. Tujuan penelitian ini yaitu mendapatkan data tradisi lisan yang tersebar pada 19 Kabupaten/Kota di Sumatera Barat. Tradisi lisan yang terkumpul yaitu terdapat perbedaan dan keunikan pada 13 kabupaten/kota.
\end{abstract}

Kata Kunci: Kebudayaan; Sumatera Barat; Tradisi Lisan

\begin{abstract}
Culture is the most important part of life that must be preserved and maintained properly. One of the 10 Objects for the Advancement of Culture (OPK) that must be preserved is the oral tradition. The problems found related to oral traditions are that fewer people know about oral traditions and writers rarely write and publish. Based on the PPKD of West Sumatra, the current condition of oral traditions requires efforts to collect existing oral traditions to be developed, so that an inventory of the oral traditions of West Sumatra can be carried out. Therefore, a study was conducted on a review of the spread of oral traditions in West Sumatra. The type of research is qualitative research with data collection techniques, namely observation and documentation, observation, literature study and interviews. The purpose of this study was to obtain a database of oral traditions spread over 19 districts/cities of West Sumatra. The oral traditions collected are 13 districts/cities that have differences and uniqueness in each region.
\end{abstract}

Keywords: Culture; Oral Tradition; West Sumatra

\section{PENDAHULUAN}

Kebudayaan adalah sebuah kebiasaan atau tradisi yang berkembang pada suatu daerah yang diturunkan dari generasi ke gerasi berikutnya (Krisnam 20217). Berdasarkan UU Pemajuan Kebudayaan No 5 Tahun 2017 terdapat 10 objek pemajuan kebudayaan (OPK) di antaranya tradisi lisan, manuskrip, adat istiadat, ritus, pengetahuan tradisional, teknologi tradisional, seni, bahasa, permainan rakyat, dan olahraga tradisional. Salah satu dari 10 Objek Pemajuan Kebudayaan yang perlu dilestarikan dan dipertahankan yaitu tradisi lisan, karena tradisi lisan ini memiliki peranan strategis dalam acara adat maupun untuk pariwisata (Masful, 2017; Sudarmanto, 2020; Arliman, 2018).

Berdasarkan Pokok Pikiran Kebudayaan Daerah Sumatera Barat (PPKD) tradisi lisan yang termasuk kedalam OPK yang harus dijaga, dimanfaatkan, dan dilestarikan untuk ketahanan di masa depan (PPKD Sumatera Barat, 2020). Tradisi lisan merupakan suatu informasi atau pesan yang disampaikan secara turun-temurun dalam suatu daerah atau kelompok. Ada tiga karakteristik tradisi secara umum. Pertama, tradisi itu merupakan kebiasaan dan sekaligus proses kegiatan yang dimiliki bersama suatu komunitas. Pengertian ini mengimplikasikan bahwa tradisi itu memiliki makna 
keberlanjutan, materi, adat, dan ungkapan verbal sebagai milik bersama yang diteruskan untuk dipraktikkan dalam kelompok masyarakat tertentu. Kedua, tradisi itu merupakan sesuatu yang menciptakan dan mengukuhkan identitas. Memilih tradisi memperkuat nilai dan keyakinan pembentukan kelompok komunitas. Ketika terjadi proses kepemilikan tradisi, pada saat itulah tradisi itu menciptakan dan mengukuhkan rasa identitas kelompok. Ketiga, tradisi itu merupakan sesuatu yang dikenal dan diakui oleh kelompok itu sebagai tradisinya (Sibarani, 2015).

Tradisi lisan termasuk dalam 10 objek pemajuan kebudayaan (OPK) dan kebudayaan nonbenda yang perlu dikembangkan dan dilestarikan. Salah satu tradisi lisan yang perlu dikembangkan yaitu tradisi lisan Sumatera Barat. Berdasarkan Pokok Pikiran Kebudayaan Daerah Sumatera Barat 2020, tradisi lisan Sumatera Barat perlu dilakukan inventarisasikan karena saat ini banyak dari penutur yang tidak merekam tradisi lisan, jumlah penutur sudah sedikit, belum adanya media untuk inventarisasi, serta generasi muda sudah tidak tertarik dengan tradisi lisan. Padahal, tradisi lisan Sumatera Barat memiliki pengaruh besar dalam acara adat dan bidang lainnya.

Saat ini makin sedikit masyarakat yang mengetahui tradisi lisan suatu daerah. Perihalnya, penutur sangat jarang menulis dan mempublikasi karyanya. Berdasarkan penyebaran angket dan observasi yang telah dilakukan, terungkap bahwa belum adanya media inventarisasi tradisi lisan, sehingga masyarakat sulit untuk menemukan karya tradisi lisan, baik digunakan untuk belajar maupun sebagai hiburan. Hal lain yang ditemukan yaitu generasi muda cenderung menyukai budaya asing dibandingka budaya sendiri, karena budaya asing dianggap lebih menarik dan sesuai dengan perkembangan zaman. Melihat kondisi tersebut, perlu dilakukan tinjauan tradisi lisan guna pelestarian dan pengembangan.

Di tengah perkembangan ilmu pengetahuan dan teknologi (IPTEK) perlu dilakukan digitalisasi di berbagai aspek agar dapat mengikuti perkembangan zaman, termasuk bidang tradisi lisan. Sebelum dilakukan digitalisasi di bidang budaya, perlu dilakukan tinjauan dan inventarisasi tradisi lisan yang ada dimasyarakat. Hal ini bertujuan untuk mempermudah dalam upaya digitalisasi bidang budaya. Berdasarkan permasalahan yang telah dijabarkan sehingga diperlukan tinjauan penyebaran tradisi lisan Sumatera Barat untuk mendapatkan data tradisi lisan dalam upaya inventarisasi. Hal ini bertujuan sebagai bentuk pelestarian tradisi lisan Sumatera Barat agar dapat terus berkembang dan diketahui oleh seluruh lapisan masyarakat.

\section{METODE}

Penelitian ini menggunakan pendekatan kualitatif. Adapun sasaran dalam penelitian ini yaitu terkumpulnya data penyebaran tradisi lisan di Sumatera Barat. Pengumpulan data yang digunakan adalah teknik pengamatan dan dokumentasi, observasi, wawancara dan studi literatur. Operasionalisasi penggunaan teknik ini bersifat fleksibel sesuai dengan kondisi yang berkembang di lapangan dengan instrumen utama pengumpul data adalah peneliti sendiri. Dengan menjadikan peneliti sebagai instrumem, maka diharapkan akan didapatkan pemahaman antara informan dan peneliti, sehingga menghasilkan data yang intersubjektif. Data yang berhasil dikumpulkan kemudian dianalisis dengan menggunakan pendekatan analisis deskriptif. Analisis dilakukan dengan cara mengatur, mengurutkan, mengelompokkan, dan mengkategorikan data, setelah itu baru dicari tematema yang kemungkinan menjadi fokus penelitian.

\section{HASIL DAN PEMBAHASAN}

Tradisi lisan adalah sebuah tradisi yang disampaikan melalui lisan yang berkembang pada suatu daerah. Trdisi lisan di Sumatera Barat meliputi bahasa, dongeng, sejarah lisan, cerita rakyat, rapalan, pantun, mitos, epos, dan tutur lisan. Berdasarkan penelitian yang dilakukan didapatkan hasil bahwa terdapat tradisi lisan Sumatera Barat di 19 Kabupaten/Kota Sumatera Barat, namun ada beberapa kabupaten/kota yang belum melaporkan data tradisi lisannya. Data penyebaran tradisi lisan di Sumatera Barat dapat dilihat pada Gambar 1. 


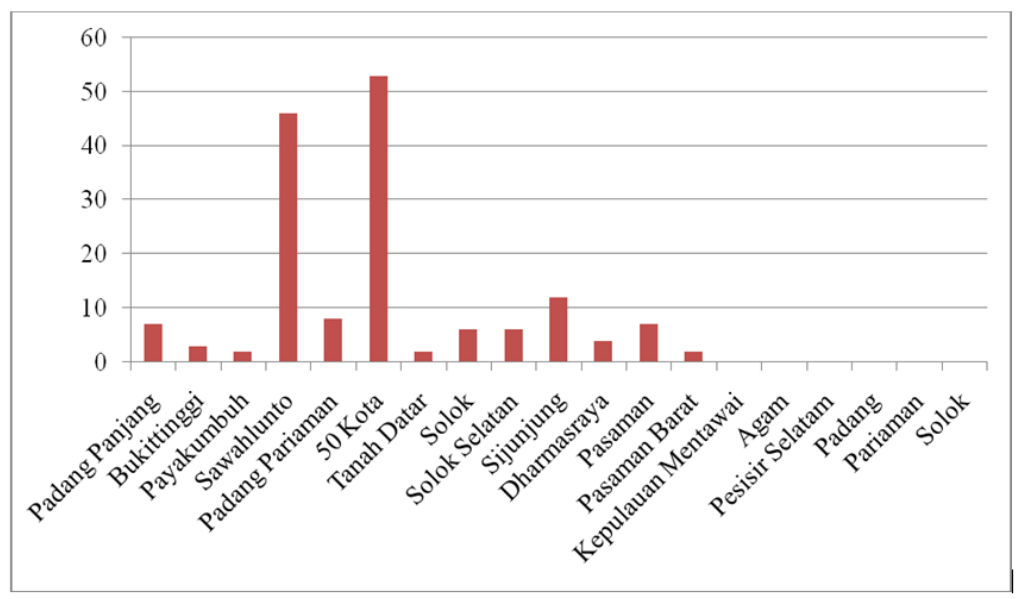

Gambar 1. Penyebaran Tradisi Lisan

Berdasarkan data yang didapatkan, terlihat dari Tabel 1, terungkap bahwa ada 6 Kabupaten/Kota yang belum terdapat pada Pokok Pikiran Kebudayaan Sumatera Barat (PPKD) diantaranya 3 Kota (Kota Padang, Kota Solok, dan Kota Pariaman) dan 3 Kabupaten (Kabupaten Kepulauan Mentawai, Kabupaten Agam dan Kabupaten Pesisir Selatan). Beberapa faktor masih minimnya rangkuman tradisi lisan Sumatera Barat yaitu identifikasi yang masih belum mendalam, tingkat lengkapnya kabupaten/kota mengisi data objek kemajuan budaya, kabuaten/kota tidak mengirim dokumen Pokok Pikiran Kebudayaan Daerah, sulitnya menemukan penutur tradisi lisan, menurunnya keinginan generasi muda dalam mempelajari tradisi lisan, dan tidak adanya wadah yang cukup untuk tradisi lisan Sumatera Barat. Tradisi lisan di Sumatera Barat memiliki perenan penting dalam kehidupan, karena tradisi lisan digunakan dalam hampir semua elemen kehidupan masyarakat seperti acara pernikahan, menyampaikan berita, komunikasi, kegiatan adat, randai, pengangkatan penghulu, tarian tradisional, dan kegiatan lainnya. Udu (2015) mengungkapkan bahwa tradisi lisan memiliki peranan sangat penting dalam kehidupan karena digunakan sebagai sarana komunikasi bagi masyarakat.

Tabel 1. Data Jumlah Tradisi Lisan

\begin{tabular}{clc}
\hline No & \multicolumn{1}{c}{ Kabupaten/Kota } & Jumlah Tradisi Lisan \\
\hline 1 & Kota Padang Panjang & 7 \\
2 & Kota Bukittinggi & 3 \\
3 & Kota Payakumbuh & 2 \\
4 & Kota Sawahlunto & 46 \\
5 & Kabupaten Padang Pariaman & 8 \\
6 & Kabupaten 50 Kota & 53 \\
7 & Kabuapaten Tanah Datar & 2 \\
8 & Kabuapaten Solok & 6 \\
9 & Kabupaten Solok Selatan & 6 \\
10 & Kabupaten Sijunjung & 12 \\
11 & Kabupaten Dharmasraya & 4 \\
12 & Kabupaten Pasaman & 7 \\
13 & Kabupaten Pasaman Barat & 2 \\
14 & Kabupaten Kepulauan Mentawai & Belum terdata \\
15 & Kabupaten Agam & Belum Terdata \\
16 & Kabupaten Pesisir Selatam & Belum Terdata \\
17 & Kota Padang & Belum Terdata
\end{tabular}


Jurnal Adat dan Budaya Vol. 3, No. 1, Tahun 2021, pp. 1-5

$\begin{array}{lll}18 & \text { Kota Pariaman } & \text { Belum Terdata } \\ 19 & \text { Kota Solok } & \text { Belum Terdata }\end{array}$

Sumber : PPKD Sumatera Barat

Berdasarkan hasil wawancara kepada penutur, penggiat budaya, masyarakat dan stakeholder terkait, didapatkan hasil bahwa tradisi lisan di Sumatera Barat memiliki keberagaman yang berbeda-beda di setiap daerahnya. Sulitnya tradisi lisan ditemukan saat ini disebabkan oleh belum ada sarana dan prasarana yang cukup untuk tradisi lisan, sedikitnya penutur tradisi lisan, serta generasi muda mulai melupakan tradisi lisan dan cenderung menyenangi budaya asing. Perlu dilakukan inventarisasi tradis lisan agar tidak hilang di masa depan, juga kolaborasi antara pemerintah, masyarakat, penggiat budaya dan penutur dalam upaya pelestarian tradisi lisan Sumatera Barat. Risha (2021) mengungkapkan bahwa pentingnya pewarisan budaya dan pelastarian budaya sedari kini dalam upaya mempertahankan warisan budaya lokal agar dapat dikenang dan berkembang di tengah-tengah masyarakat. Salah satu contoh tradisi yang ditemukan yaitu tradisi balimau yang berasal dari Bayang, Pesisir Selatan. Tradisi ini hampir tercam punah dikarenakan mulai berkurangnya pengenalan kepada generasi mudah dan fungsinya yang hampir tidak digunakan (Suniarti, 2020). Tradisi lisan lain yang ditemukan yaitu Sijobang dari Payakumbuh, hal unik dari tradisi lisan ini dibarengi dengan kotak korek api. Dalam pengembangannya secara modern, tradisi ini sudah mulai dengan barengi dengan alat musik kecapi (Zikri, 2021; Khairani, 2021; Dandes, 2020). Meskipun ditemukan didaerah lain, tapi memiliki ciri khas tersendiri. Sijobang ini biasanya menceritakan tentang ketokohan (Andrika, 2014). Tradisi lisan lain yang ditemukan yaitu Manyerak Bareh Kuning Padang Panjang, budaya ini menjadi penting dalam acara pernikahan karena jika tidak ada, maka acara pernikahan tidak dapat terlaksana (Asrianti, 2016). Tradisi lisan bagi masyarakat Sumatera Barat memiliki peranan penting baik dalam acara adat, pembelajaran, medi informasi dan hiburan (Yolanda, 2020). Meskipun masing-masing daerah memiliki berbagai variasi tradisi lisan, ini tidak menjadikan sebuah perpecahkan namun persatuan.

\section{SIMPULAN}

Penelitian yang dilakukan di Sumatera Barat ini mendapatkan hasil bahwa masing-masing daerah memiliki ciri khas terhadap tradisi lisan yang berkembang pada daerah tersebut. Terdapat 3 kota dan 3 kabupaten yang belum terdata tradisi lisannya, sehingga harus dilakukan tinjauan lanjut. Perlu dilakukan upaya pelestarian tradisi lisan Sumatera Barat agar tidak hilang dimasa yang akan datang. Dalam rangka pelestarian nya,perlu dilakukan digitalisasi terhadap tradisi lisan agar mudah dikenal dan diketahui oleh banyak orang.

\section{DAFTAR PUSTAKA}

Andrika, Y., \& Sriyanto, S. (2014). Langkah Nan Limo. LAGA-LAGA: Jurnal Seni Pertunjukan, 1(2).

Arliman, L. (2018). Peran Investasi dalam Kebijakan Pembangunan Ekonomi Bidang Pariwisata di Provinsi Sumatera Barat. Kanun Jurnal Ilmu Hukum, 20(2), 273-294.

Asriati, A. (2016). Pandangan Pemangku Adat Terhadap Tari Pasambahan di Kota Padang. Humanus, 15(1), 1-13.

Dandes, S. (2020). Mangaji Reinterpretasi Sastra Lisan dalam Komposisi Musik (Doctoral dissertation, Institut Seni Indonesia Surakarta).

Hari, S. (2015). Marhata-hata: Sastra Lisan pada Tradisi Mulak Ari di Nagari Rabi Jonggor, Kecamatan Gunung Tuleh, Kabupaten Pasaman Barat (Doctoral dissertation, STKIP PGRI Sumbar).

Khairani, I., \& Sinaga, A. N. (2020). Educational Values in the Kaba Minangkabau Text" Anggun Nan Tongga Si Magek Jabang". Lakhomi Journal Scientific Journal of Culture, 1(1), 15-22.

Krisna, E. (2017). Batombe: Warisan Budaya Bangsa dari Nagari Abai Provinsi Sumatera Barat. Madah, 7(2), 159-166.

Lauren, G. (2013). Rancang Bangun Aplikasi Pembelajaran Budaya Indonesia Untuk Anak Sekolah Dasar Berbasis Android. Jurnal Ilmiah KOMPUTASI, 12(2), 1-10.

Masful, M. F. (2017). Pariwisata syariah: suatu konsep kepercayaan dan nilai budaya lokal di daerah pedalaman Pilubang, Payakumbuh, Sumatera Barat. Jurnal The Messenger, 9(1), 1-8. 
Jurnal Adat dan Budaya Vol. 3, No. 1, Tahun 2021, pp. 1-5

Pane, B., \& Najoan, X. B. (2017). Rancang Bangun Aplikasi Game Edukasi Ragam Budaya Indonesia. Jurnal Teknik Informatika, 12(1).

Primadesi, Y. (2013). Preservasi pengetahuan dalam tradisi lisan seni pertunjukan randai di Minangkabau Sumatera Barat. Jurnal Kajian Informasi \& Perpustakaan, 1(2), 179-187.

RISHA, S. (2021). Pendokumentasian Tradisi Lisan Badabuih di Kabupaten Pesisir Selatan (Doctoral dissertation, Universitas Andalas).

Rustim, R., \& Simatupang, G. L. L. (2019). Interaksi Sosial Tradisi Bagurau Saluang Dendang Minangkabau di Sumatera Barat. Resital: Jurnal Seni Pertunjukan (Journal of Performing Arts), 20(1), 36-51.

Sibarani, R. (2015). Pendekatan antropolinguistik terhadap kajian tradisi lisan. RETORIKA: Jurnal Ilmu Bahasa, 1(1), 1-17.

Sudarmanto, B. A. (2020). Sastra Lisan Dalam Menunjang Pengembangan Pariwisata di Sumatera Selatan. Logat: Jurnal Bahasa Indonesia dan Pembelajaran, 7(1), 1-14.

Udu, S. (2015). Tradisi Lisan Bhanti-Bhanti Sebagai media Komunikasi Kultural Dalam Masyarakat Wakatobi. Humaniora, 27(1), 53-66.

Wirdanengsih, W. (2017). Enkulturasi Nilai-nilai Budaya dalam Keluarga pada Perhelatan Mandoa Khatam Al-Qur'an di Masyarakat Balai Gurah, Sumatera Barat. INSANCITA, 2(1).

Yolanda, E. (2020). Eksistensi Tradisi Manyanda pada Kehidupan Sosial Masyarakat di Nagari Talang, Kab. Solok, Sumatera Barat. Hadharah.

Zikri, M. (2021). Kucapi Saluang Dendang Dalam Acara Virtual Minang Bagurau Mendunia Grup Parewa Limo Suku Di Kecamatan Kuranji Kota Padang Provinsi Sumatera Barat (Doctoral dissertation, Institut Seni Indonesia Yogyakarta).

Zubir, Z. (2019). Dukun Patah Tulang Dan Obatan Tradisional Di Nagari Koto Anau, Kabupaten Solok Propinsi Sumatera Barat Tahun 1960-2012. HISTORIA: Jurnal Program Studi Pendidikan Sejarah, 7(1), 61-78. 